\title{
OXIDATION ASSISTED CRACK PROPAGATION OF ALLOY 718
}

\author{
Régine Molins*, Jean-Christophe Chassaigne* and Eric Andrieu** \\ *E.N.S.M.P., Centre des Matériaux P.M. Fourt, \\ B.P. 87, 91003 Evry Cedex France \\ ** E.N.S.C.T., Laboratoire Matériaux, \\ 118 Rte de Narbonne, 31077 Toulouse France
}

\begin{abstract}
The purpose of the study is to get a better understanding of the detrimental effect of environment encountered in alloy 718 at high temperature in order to design microstructures with an improved resistance to oxidation assisted cracking. Creep-fatigue tests under various oxygen partial pressures have shown the existence of a transition pressure corresponding to a brutal increase in the crack growth rate. This transition pressure corresponds to a transition in the oxidation mechanism and kinetic of alloy 718. This experimental fact has been used to modify local interaction conditions between oxidation process and mechanical behaviour during cracking process. Specific tests have then been performed, superimposing a square wave pressure on either side of the transition pressure to different mechanical cycles. The effect of an overageing treatment on the crack growth rate is examined, in relation with microstructural changes. An intergranular embrittlement mechanism is proposed which rely on the interaction between the nickel oxide nucleation and growth and the local mechanical behaviour of the alloy at the crack tip.
\end{abstract}

\footnotetext{
Superalloys $718,625,706$ and Various Derivatives Edited by E.A. Loria

The Minerals, Metals \& Materials Society, 1997
} 


\section{Introduction}

Alloy 718 is , as are many other nickel based alloys, sensitive to an oxidation assisted crack growth mechanism (1-5). Many studies emphasize the detrimental effect of environment on the mechanical behaviour of alloy 718 at high temperatures :

- crack growth rate under air are several orders of magnitude faster than under vacuum,

- sensitivity to environment depends on the microstructure,

- crack path change from transgranular under vacuum to intergranular under air environment,

- loading frequency and microstructural effects disappear under vacuum (6).

Previously, we present specific experiments that highlight the interactions between the oxidation process and the mechanical behaviour $(7,8)$. Creep-fatigue tests under various oxygen partial pressures at $650^{\circ} \mathrm{C}$ have shown the existence of a transition pressure corresponding to a brutal increase of the crack growth rate. This transition pressure is independent of the mechanical testing conditions, the loading amplitude and the frequency, but is function of the alloy chromium content. This transition is close to $10^{-3} \mathrm{mbar}$ and corresponds also to a transition in the oxidation mechanism of alloy 718. In fact, TEM and AES analyses revealed that at low pressures, chromia forms at the beginning of the oxidation whereas at high pressures, the first oxide to appear is $\mathrm{NiO}$, before the formation of a chromia layer.

The transition pressure deduced from our mechanical tests is similar to the transition identified on the oxidation process. This strongly suggests that the formation of nickel rich oxide during the early stage of oxidation is an important component of the alloy embrittlement process.

The present work is devoted to study the local interaction between oxidation and mechanical behaviour, by means of creep-fatigue tests under cycled oxygen partial pressure. The effect of an overageing treatment on the crack propagation rate is also examined, in relation with microstructural evolutions.

\section{Material and Experimental Procedures}

Alloy 718 was received as a wrought bar, heat treated, following the conventional treatment, consisting in a solutioning treatment at $955^{\circ} \mathrm{C}$ and a double ageing at $720^{\circ} \mathrm{C}$ and $620^{\circ} \mathrm{C}$. The average grain size was about $150 \mu \mathrm{m}$. After the conventional treatment, the $\gamma^{\prime}$ and $\gamma^{\prime \prime}$ strengthening phases are homogeneously distributed in the matrix. TEM examinations (figure 1) showed that the $\gamma$ precipitates were quasi-spherical (20 to $60 \mathrm{~nm}$ in diameter) and the $\gamma^{\prime \prime}$ precipitates were disc shaped particules ( 30 to $50 \mathrm{~nm}$ in diameter) sometimes associated with $\gamma^{\prime}$. A small amount of intergranular $\delta$ phases was evidenced. The volume fraction of precipitates is about $15 \%$. The chemical composition is given in table I.

Table I Chemical composition in weight percent

\begin{tabular}{llllllllll}
\hline $\mathrm{Ni}$ & $\mathrm{Cr}$ & $\mathrm{Mo}$ & $\mathrm{Fe}$ & $\mathrm{Nb}$ & $\mathrm{Ti}$ & $\mathrm{Al}$ & $\mathrm{C}$ & $\mathrm{Mn}$ & $\mathrm{Si}$ \\
\hline $\mathrm{Ral}$ & 18.6 & 3.1 & 18.5 & 5 & 0.9 & 0.4 & 0.04 & 0.2 & 0.3 \\
\hline
\end{tabular}



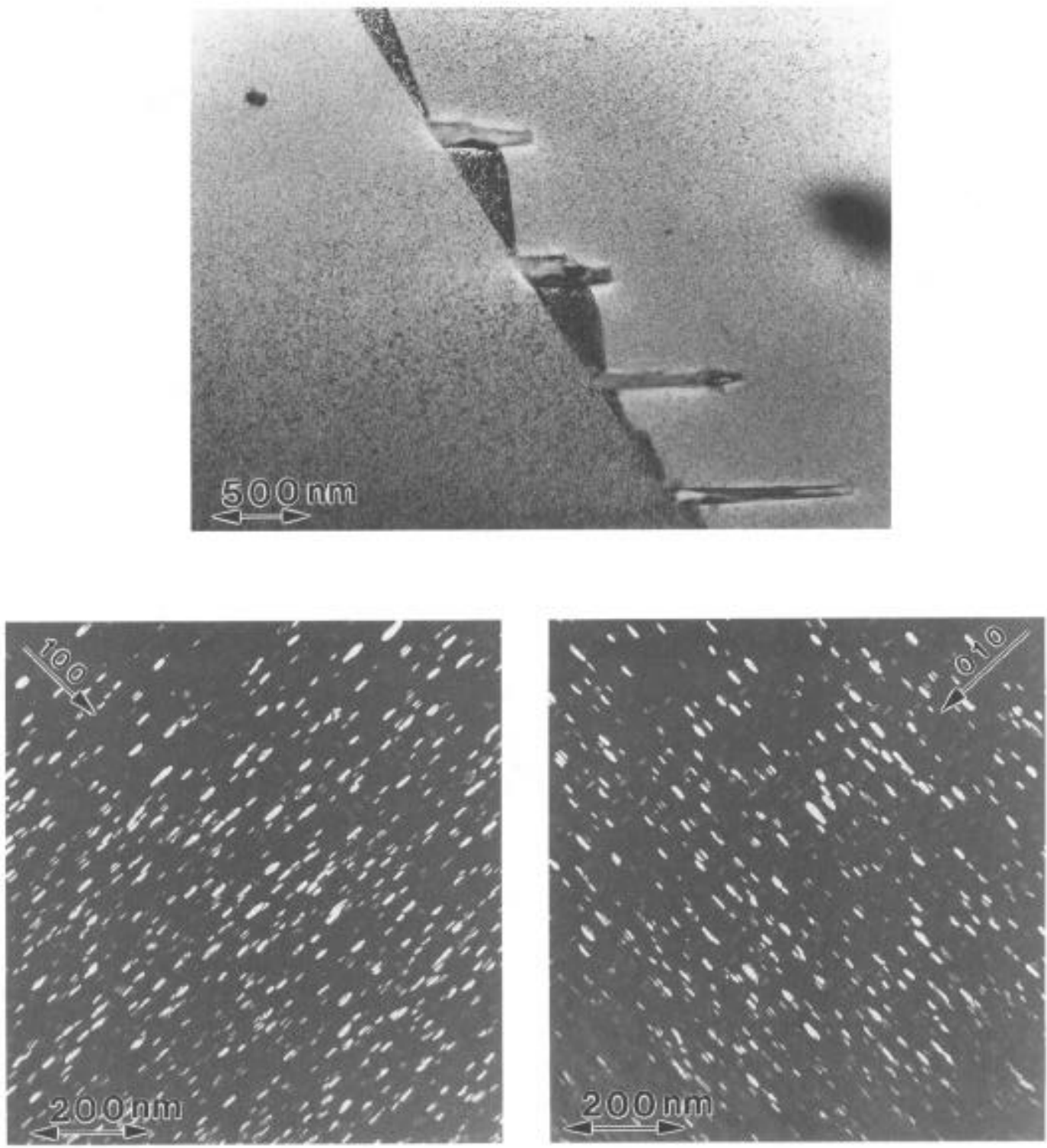

Figure 1 - TEM examinations of conventional treated alloy

Fatigue tests were performed on CT20 specimens, precracked under room and high temperatures conditions in order to induce an intergranular crack. The crack length was measured by using the potential drop technique, and also by post mortem optical measurements.

The fatigue testing frame was equipped with a high vacuum chamber, allowing the pressure to vary from $10^{-7}$ mbar to atmospheric pressure.

All tests were carried out at $650^{\circ} \mathrm{C}$, using a radiation heating system. 


\section{$\underline{\text { Results }}$}

\section{Coupling of environment and local mechanics}

The transition pressure determined in previous studies was used as a tool to study the local interaction between the oxidation process and the mechanical behaviour at the crack tip. Several experiments were carried out, superimposing a square wave oxygen pressure cycle, on either side of the transition pressure, to different mechanical cycles. The aim was to determine the damaging parts of mechanical cycles. All tests were performed at $650^{\circ} \mathrm{C}$, with a loading amplitude of $30 \mathrm{MPa}$ sqrm and a load ratio of 0.3 , in order to prevent any crack closure effect at the crack tip.

Two mechanical cycles, low cycle fatigue and creep-fatigue, were chosen. The results of the variation of the crack growth rate versus the localization of the pressure cycle are presented in figure 2 and figure 3, respectively for the triangular and trapezoidal wave forms. Concerning the triangular cycle, the pressure cycle (20s) was moved along the loading and the unloading ramps. For the trapezoidal cycle, the pressure cycle (60s) was shifted along the hold time period (300s) at maximum load. Each position of the pressure cycle was kept till a $1 \mathrm{~mm}$ propagation.

The results concerning the low cycle fatigue cycle indicate that the oxidation effect occurs between $\mathrm{R}=0.3$, corresponding to the crack opening threshold and $\mathrm{R}=0.9$, associated to an unloading threshold which corresponds to the formation of a compressive zone at the crack tip.

Between these two values, the crack propagation rate is constant assuming that in the damaging part of the cycle, the crack propagation doesn't depend on the loading $\mathrm{K}$, but is driven by the loading rate $\mathrm{dK} / \mathrm{dt}$ and consequently the deformation rate at the crack tip. Beyond $\mathrm{R}=0.9$ on the unloading ramp, the crack growth rate is close to the value obtained under vacuum.

Concerning the creep-fatigue cycle, a pressure cycle of 60 s was applied during the creep duration (300s). The evolution of the crack growth rate versus the time delay before introducing the pressure cycle shows that the detrimental effect of oxygen is efficient during the first 200 seconds of the hold time, which likely corresponds to the time necessary to reach the creep stress threshold near the crack tip.

As long as the deformation rate is upper than the threshold value, oxygen embrittlement occurs. The time necessary to obtain the threshold value depends on the local relaxation ability of the material.

'I'wo conclusions can be drawn from these tests :

- The pressure cycle duration is about ten seconds, which is the required time to produce embrittlement. The damaging process is a very local phenomenon, localized at the crack tip, attributed to the first oxide to nucleate and grow.

- The oxidation assisted cracking sensitivity depends on the stress relaxation ability of the alloy at the crack tip. A material which relax quickly would have a better propagation resistance.

For a given alloy, a microstructure exhibiting a fast relaxation of the stresses ahead of the crack would have an improved cracking resistance. This is the basic idea of the following part of this work. 

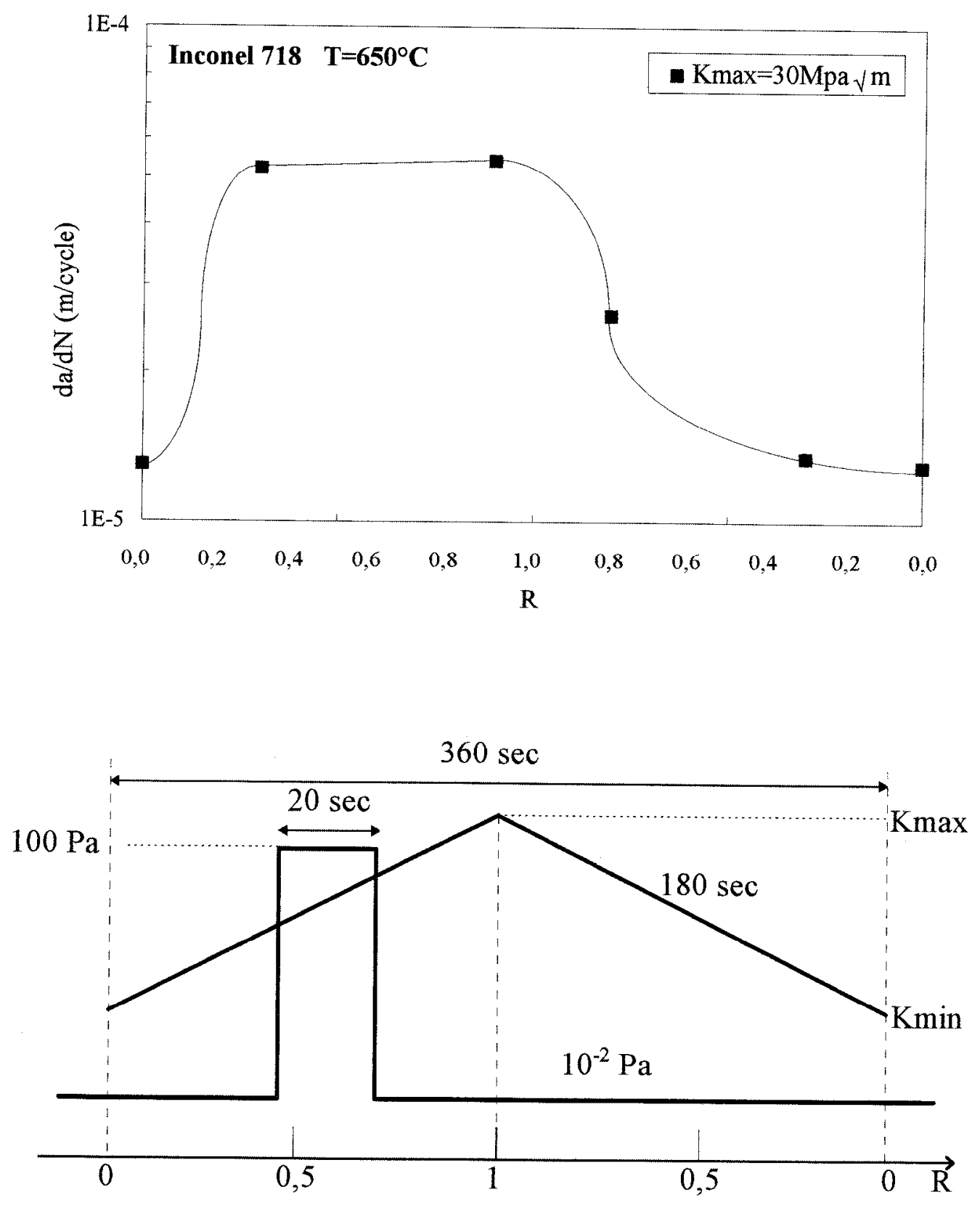

Figure 2- Fatigue crack growth rate versus the pressure cycle localization on a triangular cycle test 

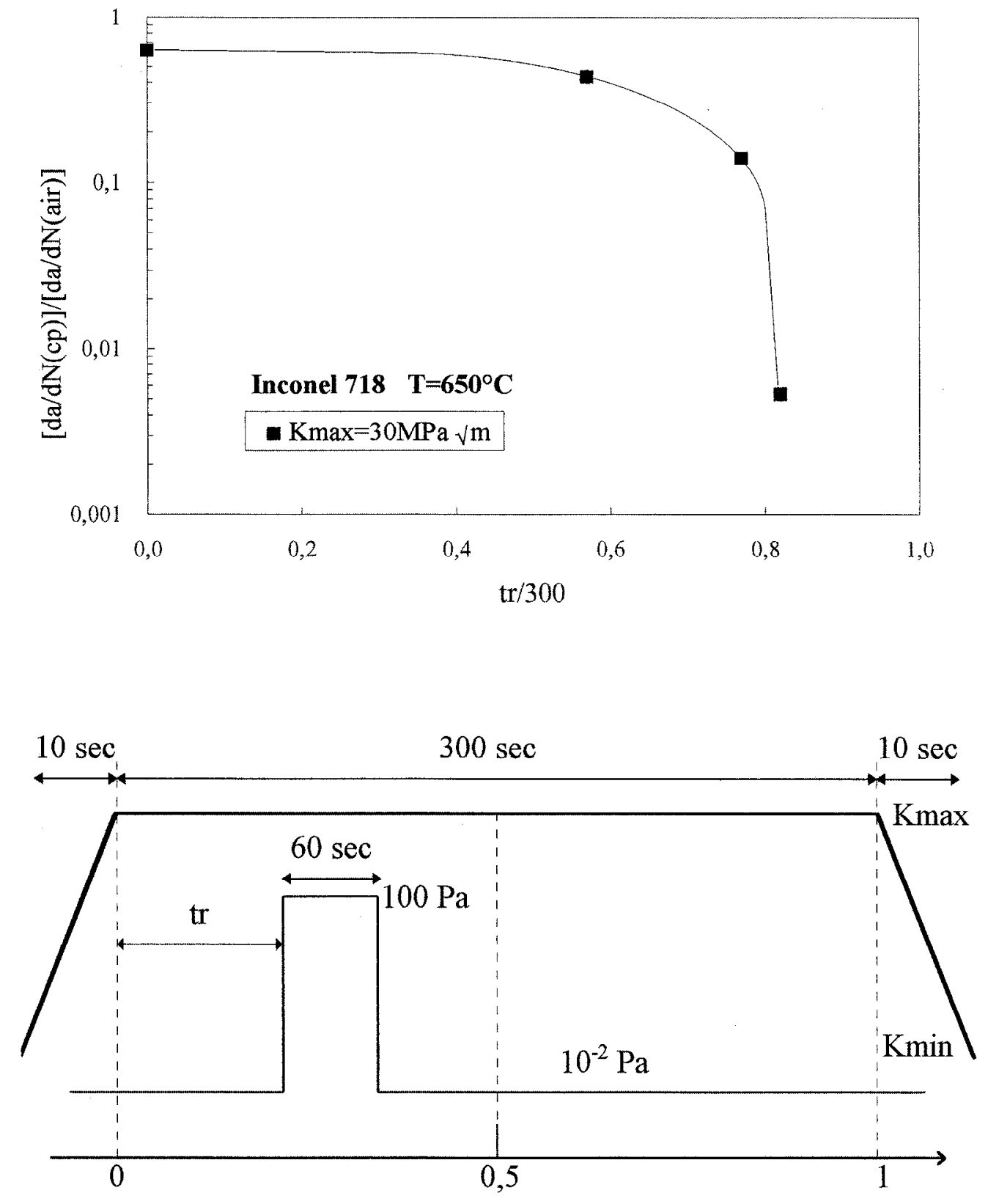

Figure 3-Fatigue crack growth rate versus the pressure cycle localization along the creep duration 


\section{Effect of an overageing treatment}

The effect of an overageing treatment on the crack propagation of alloy 718 was examined, in relation with microstructural modifications and their consequences on the relaxation behaviour of the material.

Improvement of the crack propagation resistance can be obtained by using appropriate heat treatments (9-13). A treatment of $50 \mathrm{~h}$ at $750^{\circ} \mathrm{C}$, developped by SNECMA (11), was applied on the conventional processed alloy 718 . The main features of the microstructural changes examined by TEM (figure 4 ) are the following :

- a large density of $\delta$ phase precipitation along the grain boundaries,

- an increase of the intragranular $\gamma$ and $\gamma^{\prime}$ precipitate size,

- a dissolution of $\gamma^{\prime}$ precipitates near the grain boundaries.
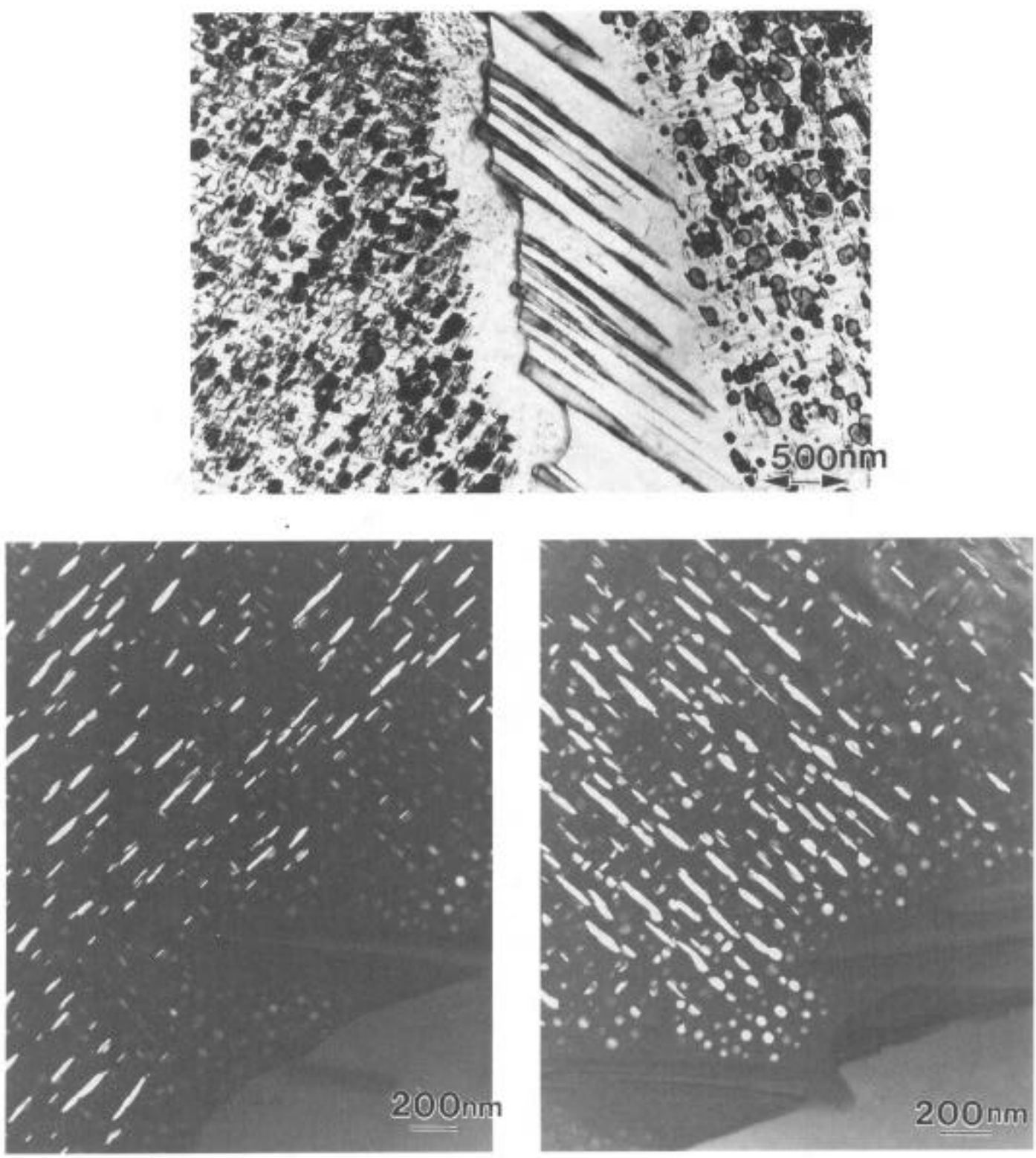

Figure 4 - TEM examinations of overaged alloy $\left(50 \mathrm{~h}\right.$ at $\left.750^{\circ} \mathrm{C}\right)$. 
According to these precipitation evolutions, the mechanical properties are modified. Comparison of tensile properties at $650^{\circ} \mathrm{C}$ is reported in table 2 .

Table II 'l'ensile properties at $650^{\circ} \mathrm{C}$

\begin{tabular}{lcc}
\hline & Conventional & overaged \\
\hline HV $20 \mathrm{~kg} / \mathrm{mm} 2$ & 441 & \\
$0.2 \% \mathrm{YS} \mathrm{MPa}$ & 1030 & 426 \\
$\mathrm{UTS} \mathrm{MPa}$ & 1177 & 965 \\
$\mathrm{EGPa}$ & 220 & 1130 \\
$\mathrm{AR} \%$ & 16 & 190 \\
& & 21 \\
\hline
\end{tabular}

The yield stress at $0.2 \%$ of overaged alloy is lower than that of conventional alloy $(6 \%)$. The ultimate tensile stress is a few decreased while the ductility is increased.

Creep-fatigue tests $(10 \mathrm{~s}-300 \mathrm{~s}-10 \mathrm{~s})$ were performed at $650^{\circ} \mathrm{C}$ under air environment on the overaged alloy and compared to the conventional alloy (figure 5).

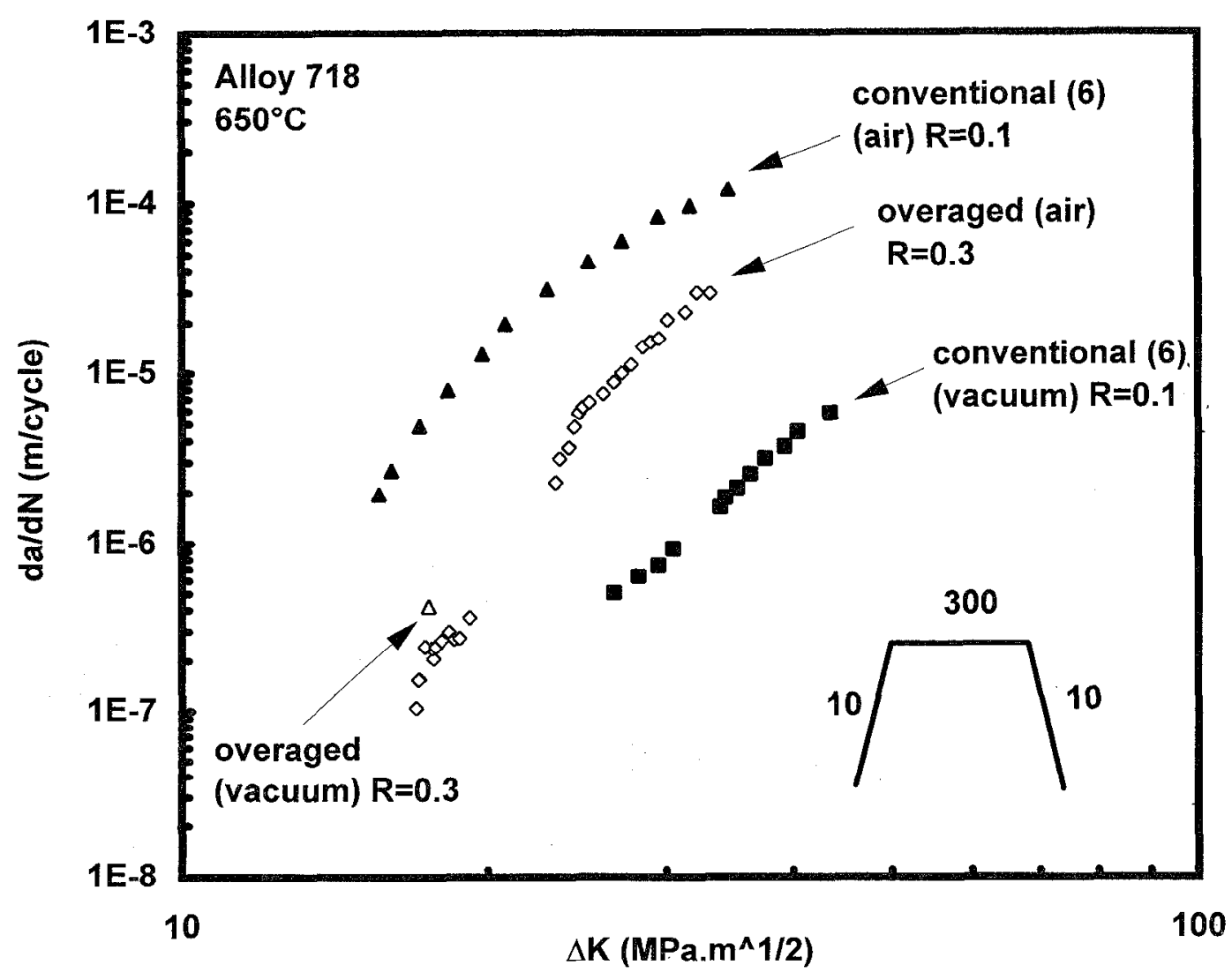

Figure 5 - Crack propagation. Comparison of conventional and overaged alloys. 
The crack growth behaviour of the overaged alloy is improved, especially at low loading amplitudes. The crack propagation is quite similar to more cracking resistant superalloys (N18). At high $\Delta \mathrm{K}$, the intergranular precipitates are deleterious to the grain boundary tenacity. The crack propagation mode changes from fully intergranular (conventional alloy) to mixed mode for the overaged alloy.

The cracking resistance obtained after ageing treatment can be explained by microstructural evolutions occurring in the material.

The increase of the size of the transgranular hardening phases promotes the homogeneity of deformation (14). Moreover, intergranular $\delta$ precipitates grow at the expense of $\gamma^{\prime \prime}$ phase, together with the formation of $\gamma^{\prime \prime}$ free zone near the grain boundaries. The material can then be considered as a composite composed of hardened grain centres surrounded with softened zones near the grain boundaries.

This leads to a local softening, by decreasing the grain boundary stress concentration.

Due to the microstructural evolutions during heat treatment, the creep resistance is decreased, the relaxation quicker and the creep propagation resistance enhanced.

\section{Discussion and Conclusions}

The coupling tests performed in the present study indicate that the embrittling process is immediate, and that oxidation and mechanical effects cannot be dissociated.

The oxidation assisted crack propagation appears in this case as a "continuous" process, involving simultaneously the local mechanical behaviour and the consequences of the nickel oxide nucleation and growth at the crack tip.

The following mechanism can then be proposed : as long as the deformation rate at the crack tip is higher than a critical level, NiO nuclei develop on the fresh crack surfaces. This cationdiffusion controlled oxidation mechanism promotes vacancy formation $(15,16)$.

Vacancy injection and migration in the grain boundary ahead of the crack tip seem to be responsible for the embrittlement phenomenon. A local recovery is also expected due to activation of climbing processes.

In the out of phase cycling conditions when the deformation rate at the crack tip is reversed to compression, the crack propagation stops. The crack tip can then be considered as a grain boundary emergence, with spontaneous formation of chromia, preventing further environmental embrittlement.

The intergranular embrittlement of nickel based superalloys in air at $650^{\circ} \mathrm{C}$ seems to be controlled by dynamic coupling between the oxidation process and the relaxation ability of the local alloy microstructure near the crack tip. The cracking resistance can be improved in two ways. The first suggestion is to improve chromia nucleation by an appropriate modification of the chemical composition (chromium content, reactive element addition). The second consists in microstructural modifications, obtained by appropriate heat treatments, leading to a quicker stress relaxation of the material near the crack tip. 


\section{References}

1. P. Shahinian, M.R. Achter, Transactions of the Metallurgical Society of AIME, 215, (1959), 37-41.

2. K. Sadananda, P. Shahinian, Metals Technology, 9, (1982), 18-25.

3. K. Sadananda, P. Shahinian, Metallurgical Transactions A 14A, (1983), 1467-1480.

4. S. Floreen, R.H. Kane, Metallurgical Transactions A 10A, (1979), 1745-1751.

5. R.H. Bricknell, D.A. Woodford, Metallurgical Transactions A 12, (1981), 425-433.

6. J.P. Pedron, A. Pineau, Materials Science and Engineering 56, (1982),143-156

7. R. Molins, J.C. Chassaigne, E. Andrieu, « Nickel based alloy intergranular embrittlement in relation with oxidation mechanisms $», 4^{\text {th }}$ International Symposium on High Temperature Corrosion and Protection of Materials, Les Embiez, France, May 1996

8. R. Molins, G. Hochstetter, J.C. Chassaigne, E. Andrieu, « Oxidation effects on the fatigue crack growth behavior of alloy 718 at high temperature », Acta Met., 45- vol.2 (1997), 663674.

9. D.J. Wilson, J. of Engineering Materials and Technology, (1973), 112-113.

10. S.P. Lynch, T.C. Radtke, B.J. Wicks, R.T. Byrnes, Fatigue and Fracture of Eng. Mat. and Structures 17, (1994), 313-325.

11. J.Y. Guedou, G. Simon, J.M. Rongvaux, in Superalloys 718, 625 and various derivatives, ed. E.A. Loria, Minerals, Met. and Mat. Society, (1994), 509-522.

12. D. Zheng, H. Ghonem, Metallurgical Transactions A 23, (1992), 3169-3171.

13. A.K. Koul, P. Au, N. Bellinger et al., in Superalloys 1988, ed. S. Reichman et al., Metallurgical Society (1988), 3-12.

14. H.H. Smith, D.J. Michel, in Ductility and thoughness considerations in elevated temperature service, (G.V. Smith, ASME, 1978), 225-246.

15. P. Hancock, in Vacancies'76, ed. R.E. Smallman, Metal Soc., (1976), 215-222.

16. H.L. Fraser, M.H. Loretto, R.E. Smallman, R.J. Wasilewski, Phil. Mag. 28, (1973), 639650. 